\title{
DIAGNOSIS AND REPAIR OF GYPSUM PLASTER COATINGS: STATISTICAL CHARACTERIZATION AND LESSONS LEARNED FROM A FIELD SURVEY
}

\author{
Ana PEREIRA, Filipe PALHA, Jorge de BRITO, José Dinis SILVESTRE \\ DECivil-Técnico, Universidade de Lisboa, Av. Rovisco Pais, 1049-001 Lisbon, Portugal
}

Received 13 Mar 2012; accepted 14 Jun 2012

\begin{abstract}
This paper provides the statistical characterization of the pathological situation of 119 gypsum plaster coatings applied to partition walls and ceilings (inner gypsum plasters - IGP), the diagnosis methods that can be used to characterize the defects and confirm their causes, and the most suitable repair solutions. The results presented in this paper were achieved via the use of an expert system developed by the authors in an extensive inspection programme covering 23 buildings. A comprehensive set of charts and their detailed statistical analysis describe the results achieved, including the characteristics (temporal, spatial and severity) and frequency of the defects in the sample and the main causes of their occurrence in walls and ceilings. The most appropriate diagnosis methods, preventive measures and repair solutions prescribed for these defects in the sample are also analyzed and the most significant correlations presented. Even though in some instances the pathological situation of IGP is common knowledge, this time it has been characterized via quantitative indicators and using a statistically significant sample, which means that important lessons can be learned.
\end{abstract}

Keywords: defect, diagnosis, gypsum plaster, inspection system, pathology, repair.

Reference to this paper should be made as follows: Pereira, A.; Palha, F.; de Brito, J.; Silvestre, J. D. 2014. Diagnosis and repair of gypsum plaster coatings: statistical characterization and lessons learned from a field survey, Journal of Civil Engineering and Management 20(4): 485-496. http://dx.doi.org/10.3846/13923730.2013.801918

\section{Introduction}

Gypsum-based solutions are the most common interior coatings used in buildings in Portugal. This solution is supplied on-site, ready-mixed, and comprises gypsum (some suppliers add lime to the mix), aggregates (siliceous and limestone calibrated sand) and admixtures (hardening retardants, plasticizing or water retentive). Some suppliers also include lightweight aggregates and/or fibres in the mix. The application by spraying includes a levelling (1 to $2 \mathrm{~cm}$ ) and a finishing layer (1 to $3 \mathrm{~cm}$ ) over the substrate (i.e. reinforced concrete slabs in ceilings and hollow bricks in walls).

Any defects that may appear in this coating when it is applied to partition walls and ceilings (inner gypsum plasters - IGP) can be overcome if a significant sample of IGP is inspected in detail and pathologically characterized. The inspection reports summarise the state of degradation of the IGP and are intended to help plan maintenance or intervention programmes. They should also recommend measures to be implemented at the design, execution and use phases to prevent the occurrence of similar defects. These measures provide vital information for everyone involved in the construction process. However, no works specifically related to inspection systems or campaigns for IGP have been found in referenced journals or in congress proceedings.
This paper describes the use of an expert system for the systematic statistical characterization of the pathology, diagnosis and repair of 119 IGP coatings and the resulting important lessons that can be learned from this field study. The IGP inspection system used has been described in detail in another paper by the authors (Pereira et al. 2010) and includes a classification of all the defects that can affect IGPs, together with their causes. This paper also presents a detailed statistical analysis of the results of the inspection programme, including the diagnosis methods used to characterize the defects and confirm their causes and the most appropriate repair solutions.

\section{Inspection programme - sample description and procedure adopted}

An inspection campaign was devised for buildings with IGP, to characterize the pathological situation of 119 IGPs and analyze the most suitable diagnosis and repair methods that can be used in each specific circumstance. This field work also made it possible to validate the expert system proposed for IGPs and the procedures adopted. The inspection plan involved the pathological characterization of 119 IGP coatings that had defects and were applied to walls (75) or ceilings (44) of 87 rooms in 23 buildings ( 22 residential and one office building). Inspection and validation files were completed at each inspection and procedures similar to those of previous inspec- 
tion campaigns for cladding were followed (in particular those devoted to gypsum plasterboards (Gaião et al. 2010b) and ceramic tiling (Silvestre, de Brito 2010b)).

Figure 1 shows the distribution of construction dates of the buildings in the sample. Most date from the 1990s $(43 \%)$ while $9 \%$ are from the fifties and sixties. The period of massive construction of buildings in Portugal is well represented: $65 \%$ were built after 1990 . Their average age is 18 years and the oldest ones were built in 1945; thus the sample can be considered as "recent buildings". The "pathological characterization" of the IGPs inspected includes the relationship between the average number of defects and their causes in the sample and the age of the building. Therefore, the pathologies found and the prescribed repair techniques differ considerably from those of old gypsum plasters (Silveira et al. 2007; Cotrim et al. 2008).

All the buildings are located in the central region of Portugal, with $83 \%$ being in the Lisbon area. Although it is the most common indoor coating used in mainland Portugal, gypsum plaster is now being used less often in the Azores because of the wet climate and the wellknown susceptibility of this coating to the action of water (Palha et al. 2011).

All the compartments of each apartment or office block were visited as part of the inspection. Therefore, IGPs with defects were found in kitchens, bathrooms and closed balconies (damp areas or compartments more susceptible to the action of water, which are $31 \%$ of the sample) and, more especially, in bedrooms and living rooms (39\% and 14\%, respectively) (Fig. 2).

\subsection{Inspection and validation files}

Inspection files contain all relevant information on the buildings and IGPs, so that different inspections can be compared. The following information is included: for each building, the construction year and the main use (housing, storage or offices); for each IGP inspected, the installation date, location, designation and constructive characterization, and finishing; and the characterization of the maintenance work undertaken during the IGP's service life. Defect mapping is recommended to supplement the inspection files in order to show the exact localization, extent and severity of the defects and to enable an adequate repair project to be prepared. This can be based on plans or photos of the building, with the help of a simplified grid.

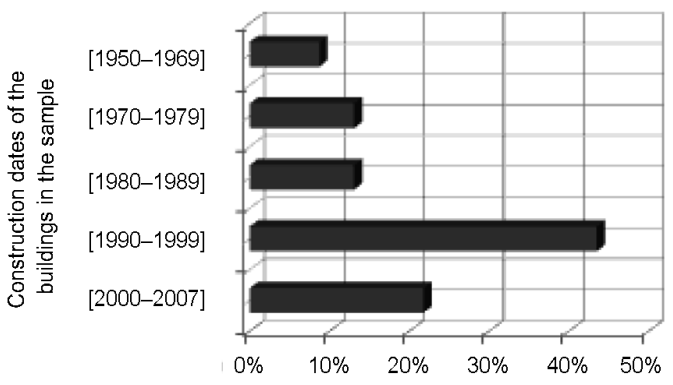

Fig. 1. Construction dates of the buildings in the sample

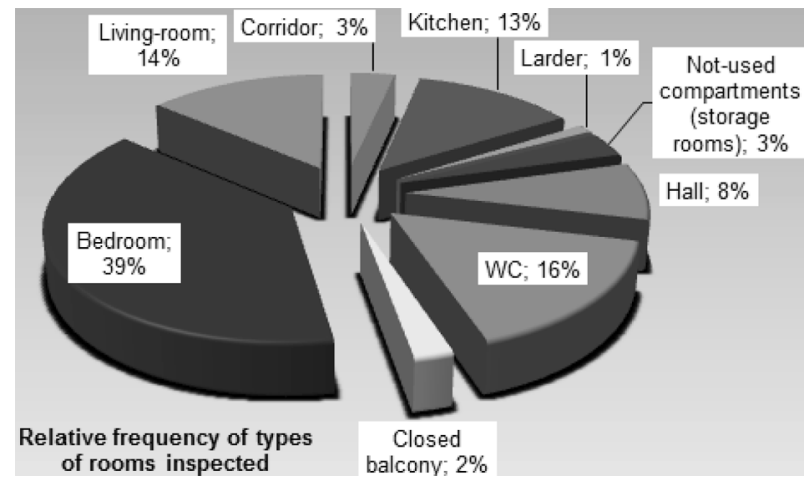

Fig. 2. Relative frequency of types of rooms inspected (Palha et al. 2011)

A validation file was also completed for each inspection to identify and record the main characteristics of the IGP defects and to validate the inspection system. The characteristics include: direct and indirect probable causes; location and size of all the defects, orientation of detachments and cracks; percentage of IGP area affected; conditions that allow the defect to progress; repair urgency and aesthetic value of the affected area; assessment methods used in the diagnosis, and the best techniques to repair the defects and/or eliminate their causes. The content of the inspection and validation files is described in full in Silvestre and de Brito (2009). The organization of the data in the validation files paved the way for the statistical analysis presented next. This analysis only covers the commonest or most serious pathological situations and does not include in-depth appraisal of the waterrelated problems/defects in IGPs $(D-P 1-$ damp, $D-C 1-$ biodeterioration and $\mathrm{D}-\mathrm{C} 2$ - efflorescence/cryptoflorescence - see Fig. 3), which are analysed in detail in another paper by the authors (Palha et al. 2011).

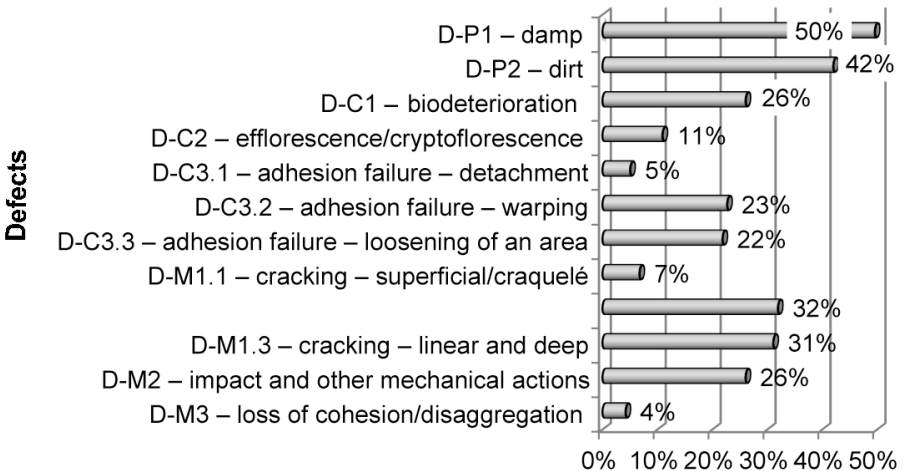

Fig. 3. Relative frequency of the defects in the sample 


\section{Diagnosis and statistical characterization of IGP pathology}

The IGP inspection system includes a classification system for defects in IGP and their causes (Pereira et al. 2010). The system embraces pathological problems of a physical, chemical or mechanical nature that can affect IGPs, in a total of 12 individual defects. The defects were defined after studying referenced pathological processes of wall coatings (Dias 2007; NG 2008; Rodrigues et al. 2005; Vergès-Belmin 2005). Each defect has an acronym: a D (for 'defect') plus a hyphen and the group reference $\mathrm{P}$ for Physical, $\mathrm{C}$ for Chemical and $\mathrm{M}$ for Mechanical (Fig. 3). A sequential number follows this second letter. The causes of the defects, the diagnosis methods and the repair techniques are classed using similar labelling.

The 53 probable causes of defects were classified and included in the inspection system in chronological order, according to the following groups: $C-A-D e s i g n$ errors, $C-B$ - Problems with materials, $C-C-$ Execution errors, $C-D-$ Exterior mechanical actions, $C-E-E n v i-$ ronmental actions, and $C-F-$ Maintenance errors (Pereira et al. 2010).

\subsection{Defects observed in the sample}

331 defects were identified in the sample of 119 IGPs (only one event per defect type was recorded for each IGP), which gave an average of 2.78 defect types per coating. Figure 3 shows the relative frequency of the defects (number of records divided by 119, the number of IGPs inspected). $D-P 1-$ damp has the highest frequency (50\%), followed by $D-P 2$ - dirt, D-M1.2 - cracking average and D-M1.3 - cracking - linear and deep (with frequency above $30 \%$ ).

Of the 331 defects found, $231(69.8 \%)$ were in walls and the rest (100 or $30.2 \%)$ in ceilings. Although more walls than ceilings were inspected ( 75 to 44$)$, this may be because of the larger area of walls in each room (even if the areas of openings, walls and doors, are excluded) compared with the area of the ceiling, and the greater exposure of the walls to human action. Moreover, the walls may be in direct contact with the exterior and be more susceptible to water infiltration than ceilings (which only suffer this problem near the edges of slabs and on the top floor).

Figure 4 shows the absolute frequency of defects in walls and ceilings. Most defects occur with similar frequency in both kinds of surfaces, except $D-P 2-\operatorname{dirt}, D$ $M 2$ - impact and other mechanical actions and those from $D-M 1$ - cracking, which occur more often in walls. The two first defects have different frequencies because the occupants have more access to the walls. Regarding group $D-M 1$ - cracking, the difference is clearly related to the inability of most of the walls to support the deformation of the beams (due to dead loads) without cracking.

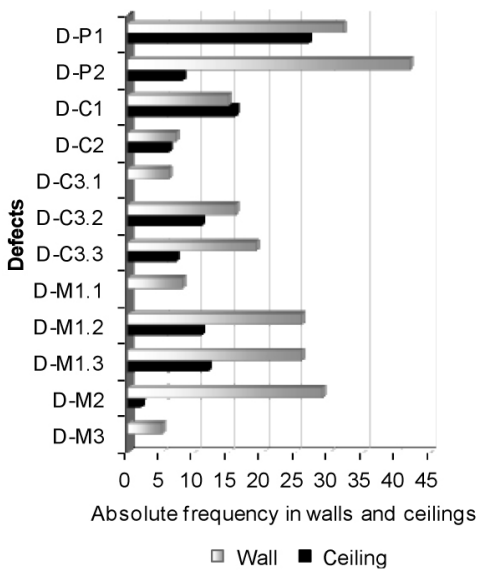

Fig. 4. Absolute frequency of defects in walls and ceilings

Figure 5 shows the relationship between the average number of defects of each type and the age of the building. There are not necessarily more defects in old buildings, but the average number of defects in the rooms of the buildings from the 1950-1969 period (0.49) is clearly higher than in the rooms of the buildings from the 2000-2007 period $(0.22)$. This shows that construction methods, performance and resistance of the materials all improved, but also that natural ageing helped to increase the number of defects (Palha et al. 2011).

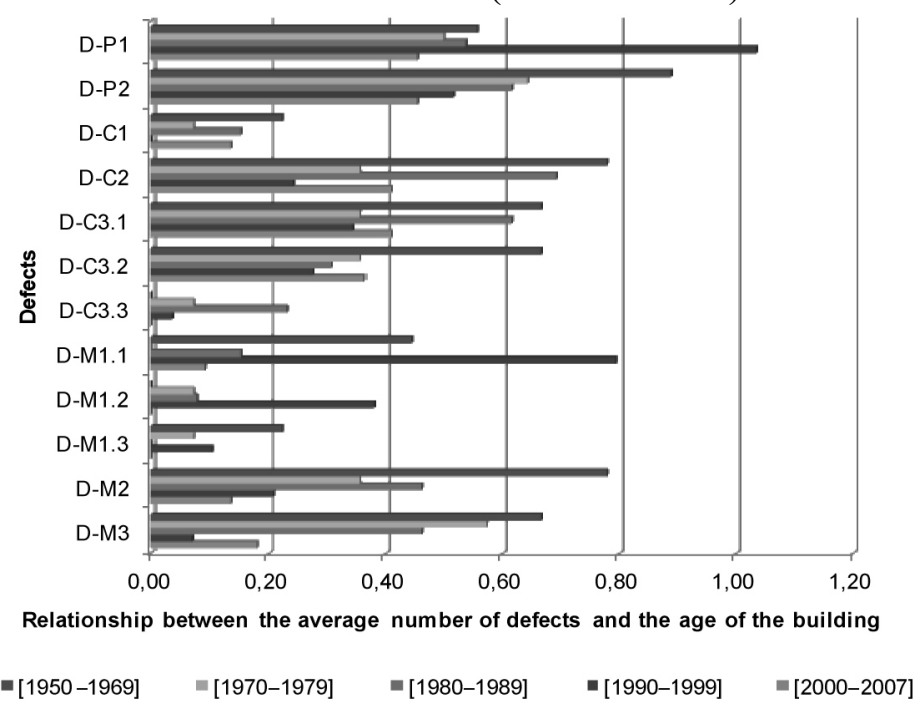

Fig. 5. Relationship between the average number of defects of each type and the age of the building 
The occurrence of defects in IGPs can be related to their surface finishing. It is generally agreed that smooth finishing, found in all the IGPs inspected, prevents defects such as dirt or biodeterioration (D-P2 and D-C1), but the type of paint used can influence this positive effect. Paints used on IGPs differ in their water vapour diffusion (permeability). Water-based paints, named "current" (74\% in the sample), offer lower resistance to the passage of water vapour and generally exhibit higher surface roughness. This enables dirt to build up and/or fungi or mould to develop more easily than enamel or water-based varnishes do $(24 \%$ of the sample, while $2 \%$ of IGPs in the sample have both water-based paint and varnish). The latter, often called "plastic paints", have low permeability to water vapour and a smoother surface finish. This prevents moisture in the room from affecting the IGP, which is good in wet areas but also has the disadvantage of potential failure of adhesion (D-C3) due to external humidity because it also prevents the wall from "breathing".

To corroborate these observations, Figure 6 shows the types of paint used on IGPs where defect $D-C 3-$ adhesion failure was found. The frequency of defects $D$ $C 3.2$ - warping and D-C3.3 - loosening of an area on IGPs coated with enamel or water-based varnish is always same as or higher than the frequency of these defects in IGPs coated with a water-based paint. This shows a strong correlation between these defects and the enamel or water-based varnish, even though $74 \%$ of IGPs have a water-based paint finish.

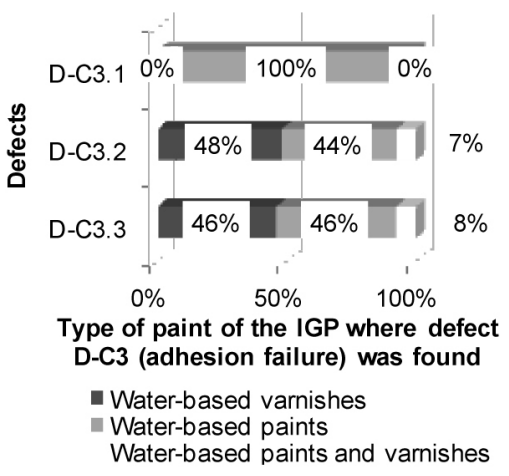

Fig. 6. Type of paint finish on IGPs where defect D-C3 (adhesion failure) was found

Every defect detected in the inspections was rated in terms of repair urgency:

-0 - Action required immediately or in a short-term

(6 months);

-1 - Action required in the medium-term

(12 months);

-2 - Action required in a long-term (reassessment in next routine inspection).

IGPs are internal coatings that's repair costs are not particularly important and they do not have the same weight in terms of the value and the risk of depreciation of the apartment or office as external coatings do (Marcinkowska, Rejment 2006). However, they should be repaired as soon as the repair urgency level of the defects detected requires it. The commonest repair urgency level is " 1 " (44\%) and the level with lowest severity (2) represents only $23 \%$ of the sample. The conclusions are different, however, for the frequency of each repair urgency level per defect (Fig. 7). Defects D-P1 - damp, D-C1 - biodeterioration, D-C2 - efflorescence/cryptoflorescence, D-C3.2 adhesion failure - warping, D-M1.1 - cracking - superficial/craquelé and D-M1.3 - cracking - linear and deep, have the highest repair urgency in more than $33 \%$ of the observations in the sample. This is probably related to their tendency to progress. If, when some of these defects are found, there is no intervention they will worsen and the IGP will deteriorate. Aesthetic defects, such as D-P1 damp and D-M2 - impact and other mechanical actions, have less demanding repair urgency levels in most situations (more than $40 \%$ frequency of level 2 ).

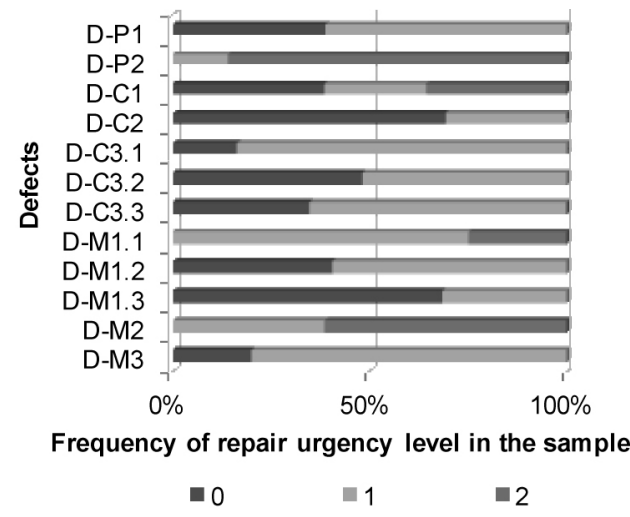

Fig. 7. Frequency of repair urgency level for each type of defect in the sample

\subsection{Probable causes of the defects observed}

3154 probable causes were identified in the inspection campaign as direct, or near, causes, or as indirect, or first, causes (Pereira et al. 2010). Therefore, 9.5 probable causes were assigned to each defect identified. It must be noted that for financial reasons the inspections consisted solely of a visual observation of the IGP and no in-situ or laboratory tests were performed. This explains the large average number of probable causes per defect, which might be reduced if a diagnostic technique could be implemented to determine the causes of the defects more easily (Palha et al. 2011).

Design errors account for $26 \%$ of the causes in the sample, and cause $C-A 1$ - incorrect application of mandatory construction rules or standards - is the most common in this group (59\%). This stems from the designer's ignorance/negligence with respect to the characteristics and limitations of materials and the requirements of the different coating systems. Causes $C-A 2$ - incorrect design/detailing of ventilation system, C-A3 - incorrect design/detailing of waterproofing system and C-A7 incorrect design/detailing of the system of protection against mechanical actions also occur frequently (more than $28 \%$ ), because they can give rise to more than one type of defect in an IGP.

"Execution errors" were the most important group of causes in the sample (almost $40 \%$ of all the causes detected 


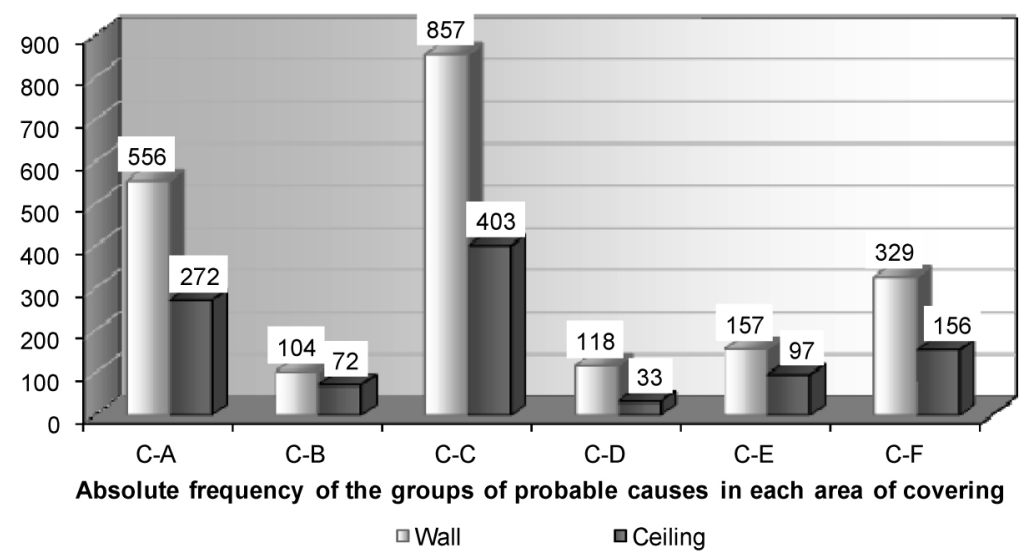

Fig. 8. Absolute frequency of the groups of probable causes in each area of coating: walls or ceilings

in the 119 IGP coatings inspected). Cause $C-C 9-a b-$ sent/insufficient mechanical preparation of substrate is one of the most important of such errors (34\%). The high frequency of this cause is understandable because the frequent transfer of stresses from the substrate to the coating is one of the main factors responsible for the premature deterioration of an IGP and contributes to the majority of its defects.

Finally, causes related to "Maintenance errors" represent about $15 \%$ of the total, of which $C-F 2$ - lack of conservation/maintenance works (47\%) and C-F1 - insufficient ventilation (35\%, especially in defects in bathrooms and kitchens) occur most often. The latter is related to errors concerning faulty design/execution of these systems or is due to improper use of the room by occupants (Palha et al. 2011).

Causes related to problems with the materials used to apply the IGP ( $6 \%$ of the causes), to "exterior mechanical actions" (5\%) and to "environmental actions" (8\%) are not analysed in detail because they occurred less often.

Figure 8 shows the absolute frequency of the groups of probable causes in each area of coating: walls or ceilings. Most of the causes were associated with defects in walls, which was expected since there were more walls in the sample (231, compared with only 100 ceilings). The relationship between the number of causes in walls and ceilings is linked to the significance of these two types of coatings in the sample. Only groups of causes $C-B-$ Problems with materials and $C-D-$ Exterior mechanical actions do deviate from this relationship. The first group only occurs $40 \%$ more often in walls than in ceilings and the second group occurs almost four times more in walls. The first situation is hard to explain, but the second is due to the greater exposure of walls to exterior mechanical actions and to stresses transmitted by the substrate.

The distribution of the average number of causes in terms of age of the room (Fig. 9) shows a fall from the older (1950-1969 with 7.2) to the recent ones (20002007 with approximately 2.5 ). This is directly related to the considerable drop in the average number of defects between these two periods (Fig. 5).

\subsection{Correlation between probable causes and defects}

From the probable causes of defect $D-P 2$ - dirt, which has an average of 4.6 probable causes per occurrence, only causes from group $C-F$ - Maintenance errors - have a frequency above 33\%: C-F2 - lack of conservation/maintenance works (98\%), C-F3 - excessive/incorrect cleaning of IGP (42\%) and C-F5 - impact or friction actions related to use, occupation or circulation of the inhabitants $(80 \%)$.

The main causes of the occurrence of defects $D$ $C 3.2$ - adhesion failure - warping and D-C3.3 - adhesion failure - loosening of an area - are presented together (Fig. 10) because they are all related to the loss of adhesion between coating and substrate. These defects have an average of 14 and 13.4 causes per occurrence, respectively. Most causes of these defects $(C-A 6-$ negligence in the conditions demanded of the substrate, C-C9 - absent/ insufficient mechanical preparation of substrate and $C$ C14 - lack of application of primer to the support (or insufficient quantity applied)) are related to the application of IGPs to substrates when the conditions to guarantee good adhesion are not in place or when the substrates have not been mechanically prepared for the possible transmission of excess stresses by the structure or from the exterior.

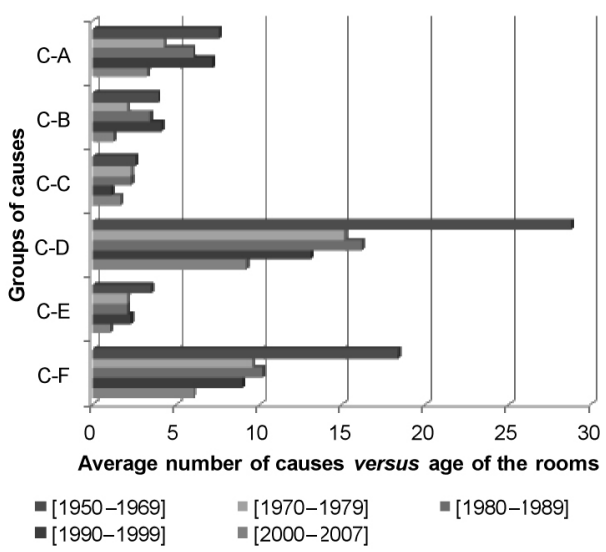

Fig. 9. Average number of causes versus age of the rooms 


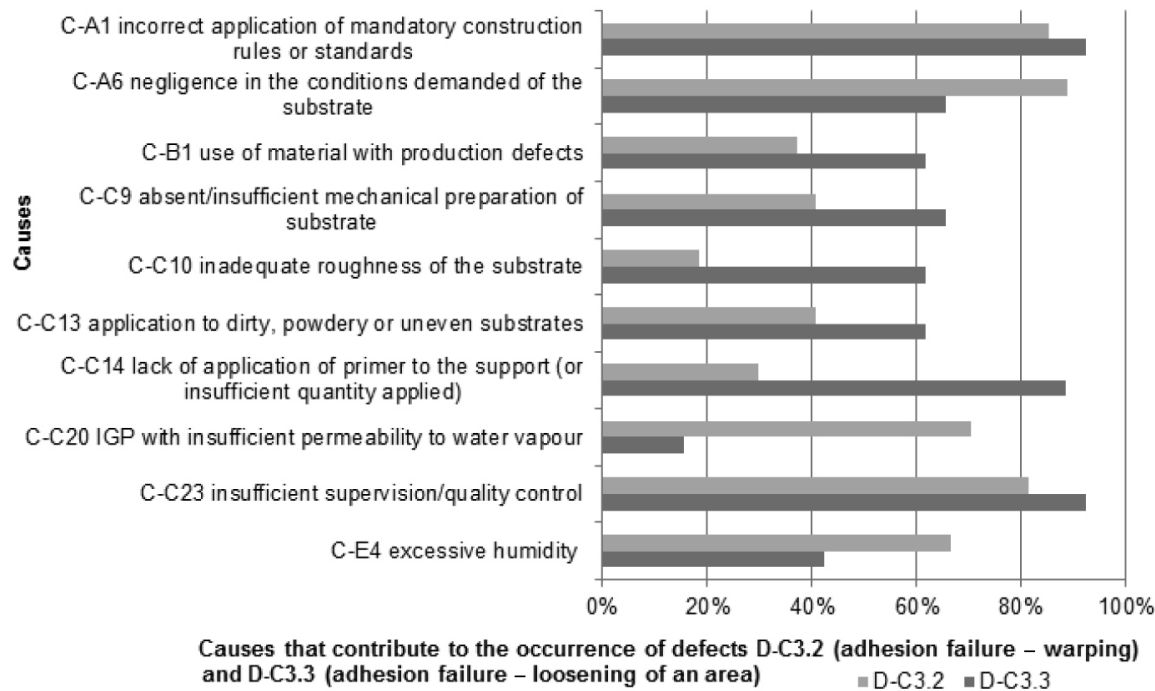

Fig. 10. Causes that contribute to the occurrence of defects D-C3.2 (adhesion failure - warping) and D-C3.3 (adhesion failure - loosening of an area)

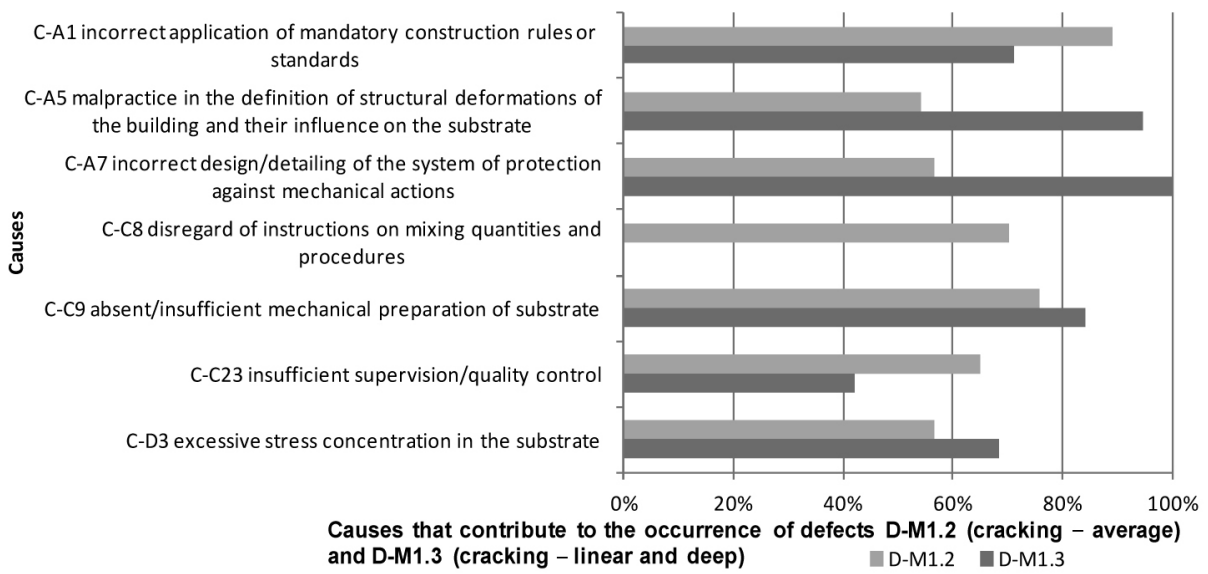

Fig. 11. Causes that contribute to the occurrence of defects D-M1.2 (cracking - average) and D-M1.3 (cracking - linear and deep)

Defects D-M1.2 - cracking - average and D-M1.3 cracking - linear and deep (Fig. 11) had an average of 9.6 and 6 probable causes per occurrence, respectively. Defect D-M1.2 is mainly caused by C-A1 (incorrect application of mandatory construction rules or standards), C-A5 (malpractice in the definition of structural deformations of the building and their influence on the substrate) and C-A7 (incorrect design/detailing of the system of protection against mechanical actions) in the design phase, and by C-C8 (disregard of instructions on mixing quantities and procedures), C-C9 (absent/insufficient mechanical preparation of substrate) and C-C23 (insufficient supervision/quality control) in the execution phase. Therefore, these elements should always be carefully planned and monitored in both the execution and use phases.

The high incidence of these causes easily explains a similar frequency of cause $C-D 3$ - excessive stress concentration in the substrate (57\%). Considering defect DM1.3, the two types of major causes that contribute to its occurrence are: those related to the design and execution of the system of protection against mechanical actions (C-A5, C-A7 and C-C9 - see Fig. 11), and those that result from mechanical actions $(C-D 3-$ excessive stress concentration in the substrate, with a relative frequency of $68 \%$ ). The causes related to the design and execution phases are particularly important because they can be more easily mitigated or prevented.

Finally, defect $D-M 2$ - impact and other mechanical actions - has an average of 6.5 probable causes per occurrence. C-F2 and C-F5 ("lack of conservation/ maintenance works" and "impact or friction actions related to use, occupation or circulation of the inhabitants", both related to $84 \%$ of the incidence of this defect) proves that the defect mainly depends on the care with which the occupants treat the coatings. Many of the situations observed, however, also lacked a protection system, which explains the high frequency of causes $C-A 7$ - incorrect design/detailing of the system of protection against mechanical actions and $\mathrm{C}-\mathrm{C} 16$ - lack of protection on protruding corners particularly exposed to impact $(100 \%$ and $90 \%$, respectively). 


\subsection{Statistical characterization of diagnosis methods for the defects observed in the sample}

The classification of diagnosis methods was proposed in Pereira et al. (2010) and includes techniques that can be used to characterize the defects in IGPs. These techniques were divided into ten groups and 1,010 were assigned in the sample, representing an average of 3.1 methods per defect detected (Palha et al. 2011). The correlation between diagnosis methods and defects in the sample is analyzed next.

The relative frequency of the diagnosis methods is presented in Figure 12. The most important ones are T-B1 (damp measurement (surface and/or environmentalhumidity)) and T-B2 (measurement of interior damp) with an incidence of more than 40\%. Method T-J2 (infrared thermography), despite occurring less often, is the third method most associated with defects (27\%). The high frequency of these three methods is due to the great importance of defect D-P1 (damp) in the sample.

Method T-F1 (micro-perforation test) has a low frequency (1\%) because of its limited scope of application, high technical requirement, high cost, and destructive nature. This method was nevertheless kept in the system because it is the best for assessing the internal resistance of a wall system.

\section{Statistical characterization of IGP repair techniques}

Repair techniques were prescribed for the defects identified in the inspections but they were not actually implemented due to time and cost constraints. Repair techniques were chosen by the authors from those contained in the proposed classification system (Pereira et al. 2010). This selection was aided in seven buildings by professionals with experience in building rehabilitation. This methodology was considered the best for validating the theoretical principles and has been already used in previous works (Garcia, de Brito 2008; Silvestre, de Brito 2010a).
437 repair techniques were considered adequate for the 331 defects observed, with an average of 1.3 techniques per defect. This can be compared with the average of 2.3 repair techniques per defect reported in previous research work (Silvestre, de Brito 2010a) on adhesive ceramic tiling. The figure in this work is just over half because only the techniques for repairing the defects were considered, while the previous work also included the techniques to eliminate the cause. The severity level of a defect was defined by considering only the situation with the greater degradation potential when there were different levels in the same room (e.g. internal and external wall or ceiling). This procedure also reduced the number of repair techniques reported. In these situations, defect mapping helps to increase the accuracy of the inspection and the consequent decisions made.

\subsection{Repair of the pathological situations observed}

The classification system of repair techniques was validated to confirm their suitability for each of the defects detected in the inspection program.

Figure 13 shows the relative frequency of the repair techniques in the sample. $R-A 1-I G P$ cleaning - was selected for $26 \%$ of the defects because it could correct most of the physical defects that are significant in the sample. But the defects were not mainly superficial, as proved by the frequency of technique $\mathrm{R}-\mathrm{Cl}-I G P \mathrm{re}$ placement $(18 \%)$, which is reflected for all the IGPs. In fact, if all the techniques suitable for the surface (R-A) and finishing layer (R-B) of the IGP are compared with all the methods applicable to the entire IGP (R-C) and to its interface with the substrate (R-D), the difference is slight $(51 \%$ versus $49 \%)$, which shows a balance of the defects in terms of depth.

Technique R-C5 (removal/replacement of corroded metal elements and repair of IGP) was only associated with $2 \%$ of the defects because of its specificity and the reduced use of unprotected metal elements within IGP coatings in newer buildings (Silveira et al. 2007). This

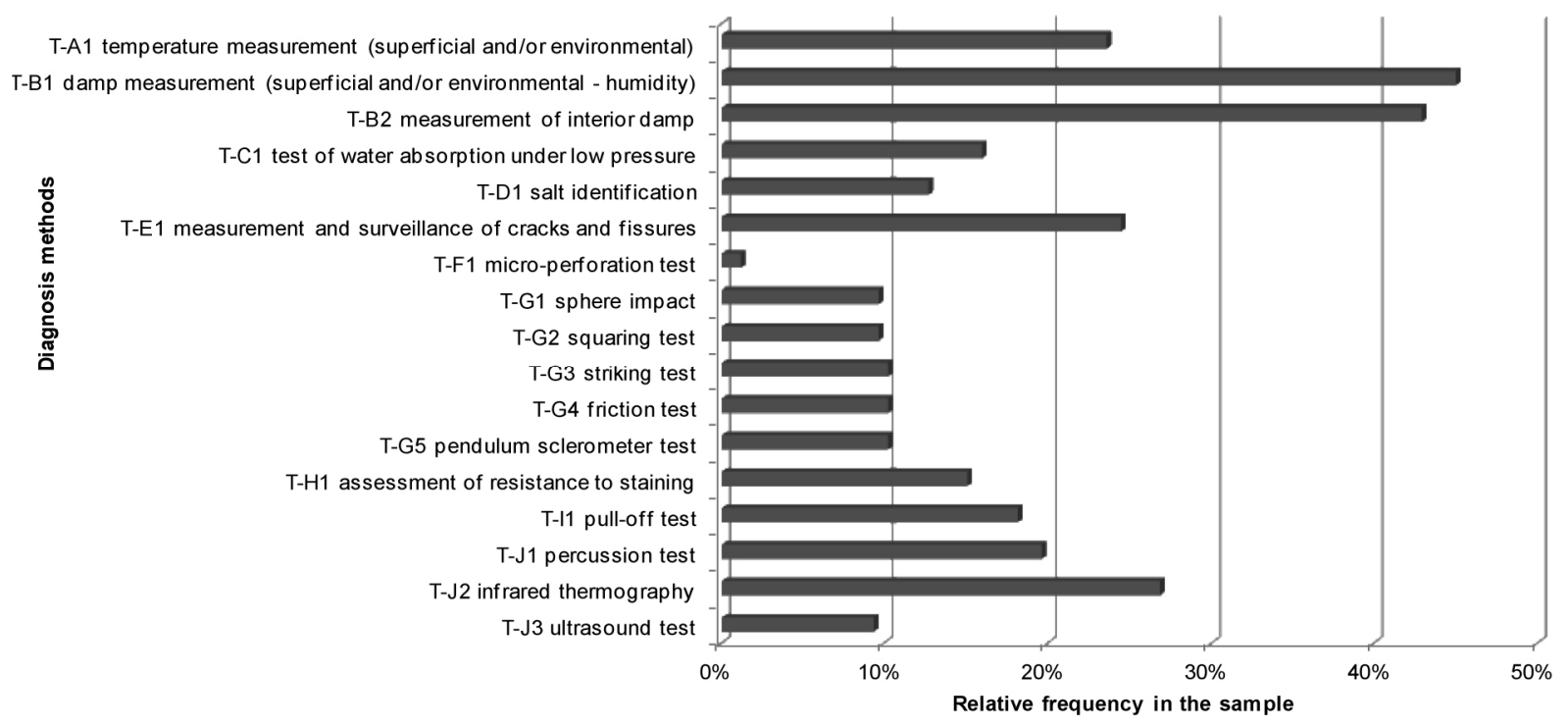

Fig. 12. Relative frequency of the diagnosis methods 


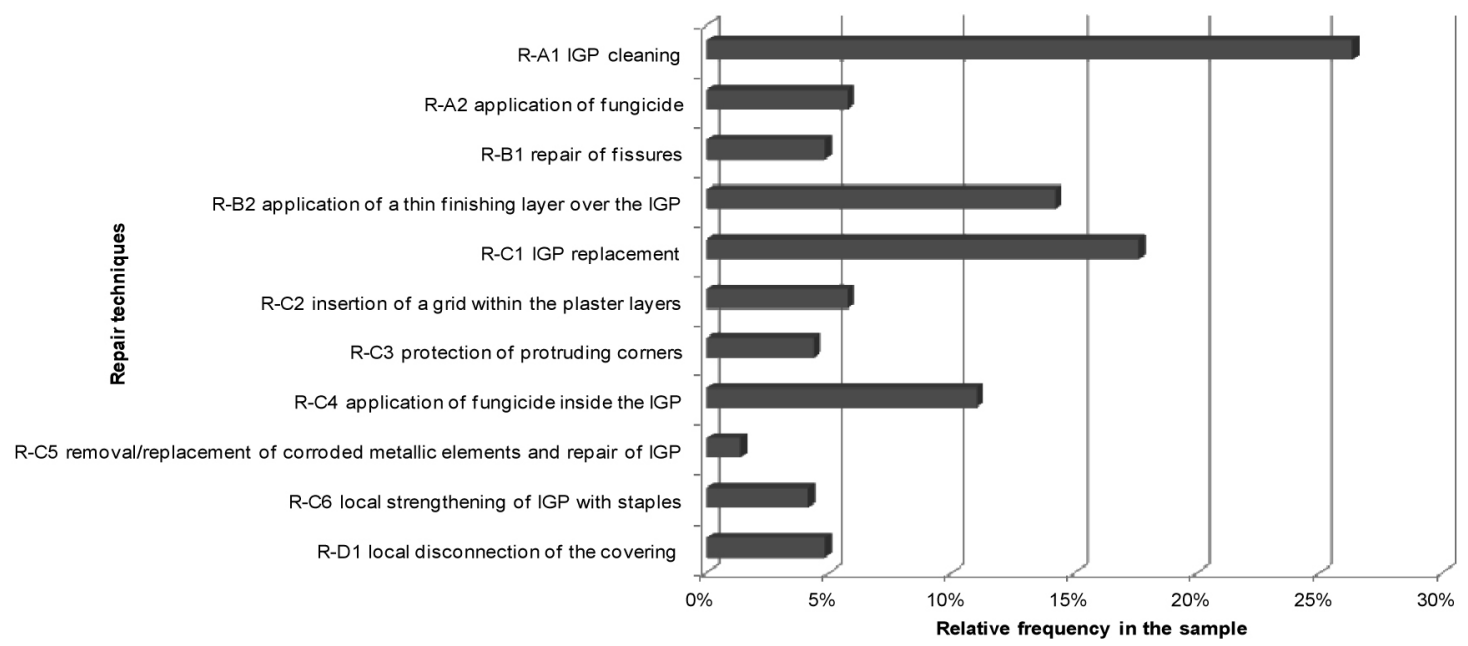

Fig. 13. Relative frequency of the repair techniques in the sample

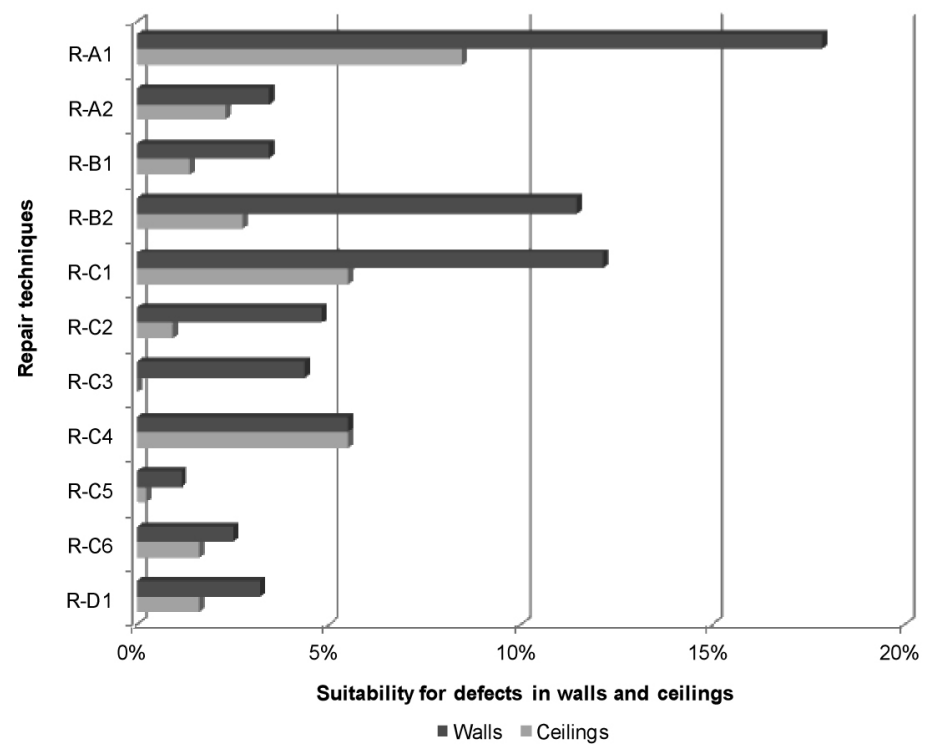

Fig. 14. Suitability of each repair technique for defects in walls and ceilings

technique was retained in the classification system because the protection of metal elements suffers degradation and nails are still used to hang objects from walls and ceilings.

Repair technique R-C4 (application of fungicide inside the IGP) had a frequency approximately twice that of R-A2 (application of fungicide). This does not imply that the latter technique is less important; it expresses the importance in the sample of rooms whose degradation was related to the action of damp, and thus with the occurrence of biodeterioration, which is better prevented with the former technique.

Finally, techniques R-B2 (application of a thin finishing layer over the IGP) and R-C1 (IGP replacement) also had a high frequency (19 and $23 \%$, respectively). These figures were already expected for the second, according to the literature, but were quite a surprise for the first. Therefore, when surface interventions (e.g. R-A1 IGP cleaning) fail to correct defects no deeper than the finishing layer, R-B2 (application of a thin finishing layer to the IGP) is a valid option. However, this must be pre- ceded by applying diagnosis methods to determine the depth to which the IGP is affected.

Figure 14 indicates the suitability of each repair technique for defects in walls and ceilings. All techniques were prescribed for walls and ceilings alike, apart from these five: $R-A 1$ - IGP cleaning; $R-B 2$ - application of a thin finishing layer over the IGP; $R-C 1$ - IGP replacement; $R-C 2$ - insertion of a grid within the plaster layers, and $R-C 3$ - protection of protruding corners. Technique R-B2 was used more often for walls because in $37 \%$ of the cases it was associated with defect D-M2 (impact and other mechanical actions), which occurs on walls $94 \%$ of the time (Fig. 4). Technique R-C2 is more suitable for walls because it is best for defect D-M1.3 (cracking linear and deep), which occurs in walls in $70 \%$ of cases.

Matching the repair techniques prescribed with the age of the buildings also led to some interesting conclusions. Technique R-A1 (IGP cleaning) is systematically associated with buildings of all ages but is more relevant in newer ones. In fact, older buildings exhibit defects whose correction goes deeper. Moreover, techniques that 
penetrate below the finishing layer (R-B) or the whole IGP (R-C) have a slightly greater frequency in pre-1980 buildings (especially $R-A 2$ - application of fungicide and $R-C 1-I G P$ replacement). In fact, recent developments in gypsum plaster production (e.g. the partial replacement of gypsum in the mix by appropriate admixtures to improve the mechanical properties of gypsum plasters (Chen et al. 2011)) can turn R-C1 into a suitable intervention to eliminate defects and significantly improve the service life of this coating solution.

In relation to the type of superficial finishing of the IGP, and despite the strong correlation between defect DC3 (adhesion failure) and the use of enamel or waterbased varnish as finishing layer (see section "Defects observed in the sample"), the relative frequency of the repair techniques is always the same or higher in the IGP with a water-based coat of paint.

\subsection{Correlation between repair techniques and defects}

This section presents the correlation between the repair techniques and the defects in the sample, in particular with respect to the frequencies of each repair technique per defect.

Technique R-A1 - "IGP cleaning" was associated with defect "damp" in almost $80 \%$ of the situations and was the one most prescribed to remedy another physical defect (D-P2 - dirt).

Almost all occurrences of defect D-C3 (adhesion failure) were associated with technique R-C1 - IGP replacement. The use of other more drastic techniques was only justified when this defect was associated with other irregularities whose repair demanded more than intervention R-C1. IGP replacement can sometimes be included in a refurbishment project after an extensive cost-benefit analysis (Zavadskas et al. 2004).

Technique R-B2 (application of a thin finishing layer to the IGP) was considered the most appropriate to solve defect D-M1.1 - cracking - superficial/craquelé, even though the insertion of a grid within the plaster (R-C2) is also a valid, but more expensive, measure.

Technique R-D1 (local disconnection of the coating) was the one most often chosen to repair defect $D-M 1.2-$ cracking - linear and deep, but it was closely followed by method R-C6 (local strengthening of IGP with staples), which has a similar performance. The reason for this difference is related to the restricted scope of application of R-C6, which requires the defect to be localized and clearly linear, (the latter is a characteristic of this defect).

Technique R-B2 (application of a thin finishing layer to the IGP) was considered the most suitable for defect $D$ M1.3 - cracking - linear and deep, along with technique $R$-C3 - protection of protruding corners. Both are suitable for this defect: the first is better when the defect is stabilized and in a regular area; the second should only be used when it is not stabilized and occurs in protruding corners.

Technique R-C1 (IGP replacement) was chosen to solve defect D-M3 (loss of cohesion/disaggregation). It is a realistic choice despite the low frequency of this defect.
The repair urgency level was defined for each defect, generally based on its extent (area affected) and stability. Stability is also very important for the choice of the most suitable repair technique. The repair urgency level is therefore not related to the depth of the defect repaired. Figure 15 presents the repair urgency level of the defects associated with each repair technique.

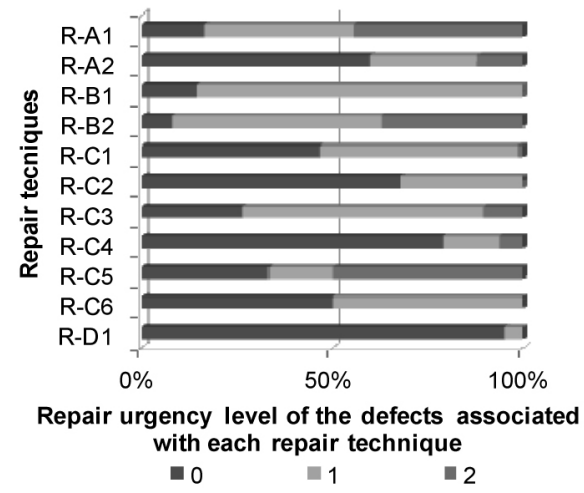

Fig. 15. Repair urgency level of the defects associated with each repair technique

Techniques related to the IGP surface (R-A) and the finishing layer (R-B) are associated with lower defect severity levels ( 1 and 2 ). The opposite is observed with more intrusive techniques (R-C and R-D): more than 50\% of the prescriptions for repair techniques R-C2 (insertion of a grid within the plaster layers), R-C6 (local strengthening of IGP with staples) and R-D1 (local disconnection of the coating) were made for defects with a higher repair urgency level (0). But methods R-A2 (application of fungicide) and R-C5 (removal/replacement of corroded metal elements and repair of IGP) are not in line with this assignment of the repair techniques by defect severity level. Technique R-A2 is a superficial intervention associated with $60 \%$ of defects with severity level 0 because it is only used when the corresponding defect (D-C1 biodeterioration) is not stabilized. Technique R-C5 is almost independent of the severity level of the IGP defects, and is directly related to the condition of the metal elements, which gives it one of the most homogeneous distributions of repair urgency levels.

Figure 16 shows the frequency of each repair technique according to the development of the corresponding defects. Technique R-A1 (IGP cleaning) does not improve the IGP characteristics, but it was associated with the majority of the stabilized defects, which seems contradictory. This may be related to the simplicity and economy of using this technique on a periodic basis, thereby making it almost a maintenance task. This repair technique can also be used to check the stabilization of defects: dirt/damp is removed and the reappearance of the defects is checked, which can justify a more serious intervention. Nor does method R-Cl (IGP replacement) improve the IGP, but it was associated with $81 \%$ of the defects not stabilized. This can be explained by the lack of techniques to prevent the reappearance of some defects when the cause of the pathological defect is not eliminated. Among these defects are: D-C3 (adhesion failure), 


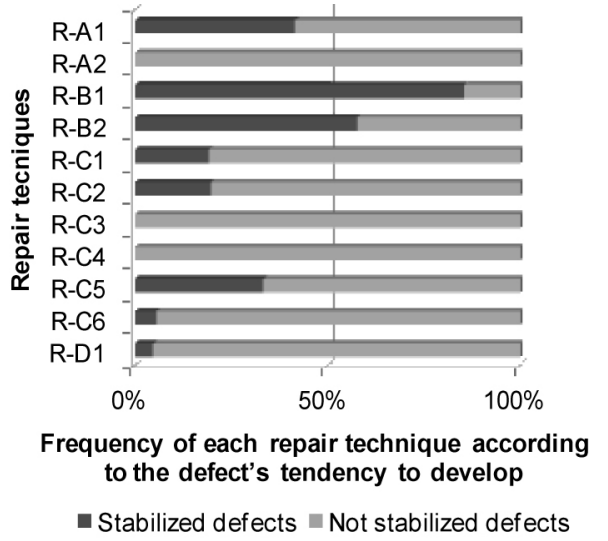

Fig. 16. Frequency of each repair technique according to the defect's tendency to develop

which represents $66 \%$ of the defects associated with this technique, $D-C 2$ - efflorescence/cryptoflorescence (14\%) and $D-M 3$ - loss of cohesion/disaggregation (5\%). Of the defects associated with techniques that improve the condition of an IGP (R-A2 - application of fungicide, $R-C 2-$ insertion of a grid within the plaster layers, $R-C 3-$ protection of protruding corners, $R$-C4 - application of fungicide inside the IGP , R-C6 - local strengthening of IGP with staples and $R-D 1$ - local disconnection of the coating), at least $80 \%$ were not stabilized. But repair techniques that do not improve an IGP were chosen for (at least) $58 \%$ of stabilized defects (except for $R-A 1-I G P$ cleaning and $R-C 1-I G P$ replacement).

\section{Lessons to be learned}

The statistical analysis presented in this paper is innovative and scientifically validated, and also statistically significant. In fact, apart from a parallel inspection system for gypsum plasterboards presented in Gaião et al. (2010a), no similar research work has been found in the specialized literature in terms of scope and aim, i.e. extensive inspection and diagnosis programmes for gypsum plaster coatings implemented on partition walls and ceilings in existing buildings (inner gypsum plasters - IGPs). The field work also allowed the validation of the expert system proposed for IGPs, thereby proving its robustness and reliability. It also provided important lessons, which are presented in this section.

\subsection{Lessons to be learned from the diagnosis of IGP pathology}

The most frequent defects in IGP coatings in walls and ceilings and their causes were highlighted and their correlation established in the different phases of the life-cycle of this coating. The location, severity and evolution of defects were also thoroughly analyzed. The pathological situation of IGPs may as well be considered as common knowledge but it has been characterized via quantitative indicators for the first time in this paper. The statistical analysis of the collected data can be therefore considered useful for professionals who design or apply IGPs.

An average of 2.78 defect types was identified per IGP, with half of them exhibiting damp. IGPs on walls show more dirt, impact marks and cracks than those on ceilings because they are accessible (the first two anomalies) and are unable to support the deformation of the beams (cracks). The average number of defects in the rooms of the buildings dating from the 1950-1969 period is more than twice that for the 2000-2007 period, which shows improvement in construction methods, performance and materials strength but also reflects natural ageing.

The inspections also revealed that the occurrence of defects in IGPs can be related to their surface finishing, and water-based paints contribute more to the accumulation of dirt and/or fungi or mould than enamel or waterbased varnishes. However, the latter triggers failure of adhesion of the coating. Therefore, moisture transfer and air infiltration in walls, especially in the envelope, should be modelled at the design phase considering the characteristics of all the materials of each layer (Nikitin, Lapko 2006; Malinowski et al. 2006).

In relation to repair urgency, defects that shows tendency to progress (i.e. damp, biodeterioration, efflorescence/cryptoflorescence, adhesion failure - warping, cracking - superficial/craquelé or linear and deep) are the biggest concern.

The commonest cause of "design error" (incorrect application of mandatory construction rules or standards) shows that designers need to improve their knowledge of the characteristics and limitations of the materials and IGP requirements. Absent/insufficient mechanical preparation of substrate is the most important "execution error", which is understandable because of the frequent transfer of stresses from the substrate to the coating that leads to the premature deterioration of the IGP and contributes to most of the defects observed in the sample. Concerning "maintenance errors", insufficient ventilation in bathrooms and kitchens, due to deficient design/execution of the IGPs or to the improper use of the room by occupants, is a cause of defects that should be dealt with right at the beginning of the IGP's service life. Therefore, ventilation solutions should be available to the final user, but without forgetting that in modern buildings ventilation systems are the most significant cause of heat loss (Carlos, Corvacho 2010).

The correlation between defects and causes in the sample showed that adhesion failure of and IGP is mostly due to applying it on substrates when the conditions are not in place to guarantee good adhesion or when the substrate has not been mechanically prepared for the possible transmission of excess stresses by the structure or exterior actions. Cracking - average is mainly caused by poor definition of structural deformations of the building and their influence on the substrate, by incorrect design/detailing of the system for protecting against mechanical actions at the design phase, by disregarding instructions on mixing quantities and procedures, by absent/insufficient mechanical preparation of substrate and by insufficient supervision/quality control in the execution phase. All these elements should always be carefully planned and monitored at both the execution and use phases. The two types of causes that contribute to the occurrence of cracking - linear and deep are related to 
the design and execution of the system that protects against mechanical actions and are those that result from mechanical actions.

\subsection{Lessons to be learned about IGP diagnosis methods}

The most important diagnosis methods in the sample are related to measuring damp (surface and/or environmental - humidity; measurement of interior damp), followed by infrared thermography. The high recurrence rate of these three methods demonstrates the importance of damp in the IGP inspected and the need for a comprehensive diagnosis in order to correctly identify the direct and indirect causes of this defect.

\subsection{Lessons to be learned about IGP repair techniques}

The suitability of the repair techniques for each type of defect was analyzed.

The fact that the frequency was similar for the group of techniques suitable for the surface and finishing layer of the IGP and for all the methods applicable to the entire IGP and to its interface with the substrate shows that there is a balance of defects in terms of depth.

Application of fungicide inside the IGP was prescribed approximately twice as often as application of fungicide, which shows the importance in the sample of rooms whose degradation was related to the action of damp, and thus to the occurrence of biodeterioration, which is better prevented with the first technique. The application of a thin finishing layer over the IGP and IGP replacement had a high frequency, which was somewhat surprising in the first case. Therefore, this is a valid option when surface interventions fail to correct defects that go no deeper than the finishing layer. However, this must be preceded by the use of diagnosis methods to determine to what depth the IGP is affected.

Relating the repair techniques prescribed to the age of the buildings showed that older buildings exhibit defects which require more than cleaning to remedy them (techniques that penetrate below the finishing layer or the whole system.

With respect to the correlation between repair techniques and defects in the sample, the application of a thin finishing layer to the IGP was considered the most suitable when cracks (linear and deep) are found, along with the protection of protruding corners; the first is better when the defect is stabilized and in a current area, and the second when it is not stabilized and occurs in protruding corners.

Techniques related to the IGP surface and the finishing layer are associated with less severe defects, but the opposite is observed with more intrusive techniques like the insertion of a reinforcing grid within the plaster layers, local strengthening of IGP with staples and local detachment of the coating. As stated, the stabilization or development of the defects is a crucial factor in the choice of repair techniques. But this is less connected with the depth of the defects than it is with the character- istics of each repair technique. Defects whose causes have not been eliminated are not usually regarded as stable. Therefore, repair techniques should not only restore the initial condition of the IGP but also improve it in order to prevent recurrence of the defect.

\section{Acknowledgements}

The authors gratefully acknowledge the support of the ICIST Research Institute, Técnico, Universidade de Lisboa, and of the FCT (Foundation for Science and Technology).

\section{References}

Carlos, J.; Corvacho, H. 2010. Retrofit measures in old elementary school buildings towards energy efficiency, Journal of Civil Engineering and Management 16(4): 567-576. http://dx.doi.org/10.3846/jcem.2010.63

Chen, M.; Yu, Y.; Feng, C.; Li, D. 2011. Study on flue gas desulphurization gypsum plaster, Applied Mechanics and Materials 71-78: 842-846.

Cotrim, H.; Veiga, R.; de Brito, J. 2008. Freixo palace: rehabilitation of decorative gypsum plasters, Construction and Building Materials 22(1): 41-49. http://dx.doi.org/10.1016/j.conbuildmat.2006.05.060

Dias, T. 2007. Salt crystallization in plastered or rendered walls: PhD Thesis in Civil Engineering at Instituto Superior Técnico, Technical University of Lisbon, Portugal.

Gaião, C.; de Brito, J.; Silvestre, J. D. 2010a. Inspection and diagnosis of gypsum plasterboard walls, Journal of Performance of Constructed Facilities 25(3): 172-180. http://dx.doi.org/10.1061/(ASCE)CF.1943-5509.0000149

Gaião, C.; de Brito, J.; Silvestre, J. D. 2010b. Technical note: gypsum plasterboard walls: inspection, pathological characterization and statistical survey using an expert system, Materiales de Construcción 62(306): 285-297. http://dx.doi.org/10.3989/mc.2011.62210

Garcia, J.; de Brito, J. 2008. Inspection and diagnosis of epoxy resin industrial floor coatings, Journal of Materials in Civil Engineering 20(2): 128-136. http://dx.doi.org/10.1061/(ASCE)08991561(2008)20:2(128)

Malinowski, P.; Polarczyk, I.; Piotrowski, J. 2006. Neural model of residential building air infiltration process, Journal of Civil Engineering and Management 12(1): 83-88.

Marcinkowska, E.; Rejment, M. 2006. Effect of risk on economic efficiency of overcladding system, Journal of Civil Engineering and Management 12(3): 247-253.

$N G$ 2008. Veneer plaster systems. $12^{\text {th }}$ ed. Gypsum Construction Guide, National Gypsum. 14 p.

Nikitin, V.; Lapko, A. 2006. On modelling heat and moisture transfer in sandwich wall and slab structures, Journal of Civil Engineering and Management 12(4): 337-343.

Palha, F.; Pereira, A.; de Brito, J.; Silvestre, J. D. 2011. The effect of water in the degradation of gypsum plasters: inspection, diagnosis and repair, Journal of Performance of Constructed Facilities 26(4): 424-432. http://dx.doi.org/10.1061/(ASCE)CF.1943-5509.0000258

Pereira, A.; Palha, F.; de Brito, J.; Silvestre, J. D. 2010. Inspection and diagnosis system for gypsum plasters in partition walls and ceilings, Construction and Building Materials 25(4): 2146-2156.

http://dx.doi.org/10.1016/j.conbuildmat.2010.11.015 
Rodrigues, J.; Gonçalves, T.; Luxán, M.; Vergès-Belmin, V.; Wijffels, T.; Lubelli, B. 2005. A proposal for classification of salt crystallisation behaviour of plasters and renders. COMPASS end-report.

Silveira, P.; Veiga, R.; de Brito, J. 2007. Gypsum coatings in ancient buildings, Construction and Building Materials 21(1): 126-131.

http://dx.doi.org/10.1016/j.conbuildmat.2005.06.035

Silvestre, J. D.; de Brito, J. 2010a. Inspection and repair of ceramic tiling within a building management system, Journal of Materials in Civil Engineering 22(1): 39-48. http://dx.doi.org/10.1061/(ASCE)08991561(2010)22:1(39)

Silvestre, J. D.; de Brito, J. 2010b. Ceramic tiling in building façades: inspection and pathological characterization using an expert system, Construction and Building Materials 25(4): 1560-1571.

http://dx.doi.org/10.1016/j.conbuildmat.2010.09.039
Silvestre, J. D.; de Brito, J. 2009. Ceramic tiling inspection system, Construction and Building Materials 23(2): 653668. http://dx.doi.org/10.1016/j.conbuildmat.2008.02.007

Vergès-Belmin, V.; Wijffels, T.; Gonçalves, T.; Nasraoui, M. 2005. The COMPASS salt crystallization test (COMPASS-TEST) as way to figure out how salts migrate and accumulate in renovation plasters. COMPASS end-report.

Zavadskas, E.; Kaklauskas, A.; Gulbinas, A. 2004. Multiple criteria decision support web-based system for building refurbishment, Journal of Civil Engineering and Management 10(1): 77-85. http://dx.doi.org/10.1080/13923730.2004.9636289

Ana PEREIRA holds a Master's degree in Civil Engineering from Técnico-Lisboa, Universidade de Lisboa, Portugal. Her research interests include inspection and diagnosis systems for construction elements.

Filipe PALHA holds a Master's degree in Civil Engineering from Técnico-Lisboa, Universidade de Lisboa, Portugal. His research interests include inspection and diagnosis systems for construction elements.

Jorge de BRITO is a Full Professor at Técnico-Lisboa, Universidade de Lisboa, Portugal. He is a member of CIB W80, W86 and W115. His research interests include the performance, pathology, in situ testing, diagnosis, maintenance, rehabilitation and service life prediction of buildings and construction elements and sustainable construction.

José Dinis SILVESTRE is an Assistant Professor at Técnico-Lisboa, Universidade de Lisboa, Portugal. He is a member of CIB W80 and W115. His research interests include building pathology and rehabilitation and life-cycle assessment of construction materials and assemblies. 